\title{
Evolutionary Analysis of OAT Gene Family in River and Swamp Buffalo: Potential Role of SLCO3A1 Gene in Milk Performance
}

\author{
Xiaoya Ma ${ }^{1}$, Shasha Liang ${ }^{1}$, Aixin Liang ${ }^{2}$, Hossam E. Rushdi ${ }^{3}\left(\mathbb{D}\right.$ and Tingxian Deng ${ }^{1, *}$ \\ 1 Key Laboratory of Buffalo Genetics, Breeding and Reproduction Technology, Buffalo Research Institute, \\ Chinese Academy of Agricultural Sciences, Nanning 530001, China; maxiaoya8899@163.com (X.M.); \\ cangshucangshu@126.com (S.L.) \\ 2 Key Laboratory of Agricultural Animal Genetics, Breeding and Reproduction of Ministry of Education, \\ Huazhong Agricultural University, Wuhan 430070, China; lax.pipi@mail.hzau.edu.cn \\ 3 Department of Animal Production, Faculty of Agriculture, Cairo University, 12613 Giza, Egypt; \\ hosamrushdi@agr.cu.edu.eg \\ * Correspondence: dtx282000@163.com; Tel.: +86-771-3338816
}

Citation: Ma, X.; Liang, S.; Liang, A.; Rushdi, H.E.; Deng, T. Evolutionary Analysis of OAT Gene Family in River and Swamp Buffalo: Potential Role of SLCO3A1 Gene in Milk Performance. Genes 2021, 12, 1394. https://doi.org/10.3390/genes 12091394

Academic Editor: Juan-Jose Arranz

Received: 26 July 2021

Accepted: 7 September 2021

Published: 10 September 2021

Publisher's Note: MDPI stays neutral with regard to jurisdictional claims in published maps and institutional affiliations.

Copyright: (c) 2021 by the authors. Licensee MDPI, Basel, Switzerland. This article is an open access article distributed under the terms and conditions of the Creative Commons Attribution (CC BY) license (https:/ / creativecommons.org/licenses/by/ $4.0 /)$.

\begin{abstract}
The organic anion transporter (OAT) family is the subfamily of the solute carrier (SLC) superfamily, which plays a vital role in regulating essential nutrients in milk. However, little is known about the members' identification, evolutionary basis, and function characteristics of OAT genes associated with milk performance in buffalo. Comparative genomic analyses were performed to identify the potential role of buffalo OAT genes in milk performance in this study. The results showed that a total of 10 and 7 OAT genes were identified in river buffalo and swamp buffalo, respectively. These sequences clustered into three groups based on their phylogenetic relationship and had similar motif patterns and gene structures in the same groups. Moreover, the river-specific expansions and homologous loss of OAT genes occurred in the two buffalo subspecies during the evolutionary process. Notably, the duplicated SLCO3A1 gene specific to river buffalo showed higher expression level in mammary gland tissue than that of swamp buffalo. These findings highlight some promising candidate genes that could be potentially utilized to accelerate the genetic progress in buffalo breeding programs. However, the identified candidate genes require further validation in a larger cohort for use in the genomic selection of buffalo for milk production.
\end{abstract}

Keywords: buffalo; milk yield; organic anion transporter; gene family

\section{Introduction}

The organic anion transporter (OAT) family is the secondary/tertiary active transporter protein falling into the subfamily of the solute carrier (SLC) superfamily [1]. This family, which has been determined to have six members, comprises a group of over 10 transmembrane proteins. Evidence revealed that the OAT family is present in many mammals and plays a vital role in regulating essential nutrients in milk [2]. Ibeagha-Awemu et al. [3] reported that the SCLO3A1 gene was one of the candidate genes influencing cow milk traits. However, little is known about the function and characteristics of the OAT family affecting milk performance in buffalo.

Several similar genes constitute a particular gene family formed by duplication of an ancestral gene with similar biological functions. Identifying members, evolution, and expression analysis of the gene families has become the core content of comparative genome analysis, which helps in the systematic and comprehensive understanding of their putative functions. Evidence has revealed that gene duplication, including tandem and segmental duplication, plays a vital role in accelerating gene family expansion and genome evolution [4-6]. Moreover, gene duplication is considered as the single most important factor responsible for the formation of novel genes [7] and functional divergence [8]. Therefore, 
gene family analysis can help to better understand the evolution, function divergence, and formation history of the candidate genes. This strategy provides a useful reference for further investigating the biological mechanisms underlying species differentiation, biodiversity formation, and phenotypic diversity. In this regard, Rehman et al. [9] reported a gene family analysis of heat-shock proteins (HSP) that provides an understanding of HSPs in buffalo at the molecular level for the first time. In plants, Meng et al. [10] found that segmental duplication (SD) and whole-genome duplication (WGD) events are the major driving force for the expansion of the MADS-box gene family in pear, and their functional divergence of some orthologous genes originated from a common ancestor. The use of comparative genomics analysis will help understand the functional differentiation of the candidate gene and its effect on phenotypic diversity.

Water buffalo (Bubalus bubalis) is an important dairy animal mainly distributed in tropical and subtropical areas. Buffalo is divided into two subspecies: river buffalo (Bu. bubalis bubalis, $2 n=50$ ) and swamp buffalo (Bu. bubalis carabanesis, $2 n=48)$, which differ in their chromosome number, morphology, and type of production specialization [11]. In general, river buffalo are mainly reared for milk production, whereas swamp buffalo are used for draught [12]. Compared to dairy cattle, lower milk performance is one of the main constraints in the current buffalo dairy industry. In this regard, we explored the evolution and function divergence of the OAT family genes in river and swamp buffalo based on the comparative genomic analysis. These results provide useful information for illuminating the biological functions of the OAT family genes affecting milk performance in buffalo.

\section{Materials and Methods}

\subsection{Ethics Statements}

Animal Care and Use Committee approval was not required for this study because the data were obtained from an existing database.

\subsection{Identification of $O A T$ Gene Family}

A total of 7 mammals' genome datasets were downloaded from the Genome database of NCBI and National Genomics Data Center (NGDC, BIG), namely, human (GRCh38.p12), cattle (ARS-UCD1.2), goat (ARS1), sheep (Oar_rambouillet_v1.0), horse (EquCab3.0), river buffalo (UOA_WB_1), and swamp buffalo (Accession number: GWHAAJZ00000000). The known protein sequences of the OAT gene family were downloaded from UniPort [13] and used to build hidden Markov model (HMM) profiles using HMMER v3.3.1 software [14]. All OAT proteins were searched in the species mentioned above by HMMER v3.3.1 software [14] with default parameters.

\subsection{Gene Duplication Analysis of OAT Gene Family}

Chromosomal locations of each OAT gene in river and swamp buffalo were obtained from their genome resources. The identification of orthologous OAT genes in river and swamp buffalo was analyzed and visualized by TBtools (v1.051) software [15] with the one-step MCScanX command. For each orthologous gene pair, the ratio between the nonsynonymous substitution rate (Ka) and the synonymous substitution rate (Ks) was computed by TBtools (v1.051) software [15]. The divergence time for each orthologous gene pair was estimated by $\mathrm{T}=\mathrm{Ks} / 2 \lambda \times 10^{-6}$ million years ago (Mya) [16], where $\mathrm{T}$ is the absolute time of divergence, Ks is the synonymous substitution rate, and $\lambda$ is the clock-like rate in buffalo of $1.26 \times 10^{-8}$ [17].

\subsection{Sequence Analysis of OAT Gene Family}

All identified OAT sequences were subjected to the ExPASy proteomics server to estimate their molecular weight (MW) and isoelectric points (pI). These protein sequences were further used for multiple alignments and the phylogeny tree construction implemented in MEGA-X software [18]. The motif pattern and gene structures of OAT family members were analyzed using the MEME platform and TBtools (v1.051) software [15], respectively. 
The motif element was annotated using the Pfam program. Moreover, two-kbp upstream promoter sequences from the start codon (ATG) of all orthologous OAT genes in river and swamp buffalo were also extracted by TBtools (v1.051) software [15]. They were further applied to analyze cis-elements using the TFBSTools (v3.11) package [19] in R.

\subsection{Comparative Transcriptomic Analysis of the OAT Genes in Buffalo Subspecies}

Two published RNA-seq data (BioProject: PRJEB4351 and BIGD: CRA002325) were selected and employed to explore the tissue expression patterns of the OAT gene family between the river and swamp buffalo. In the PRJEB4351 project, there are a total of 30 tissues from Mediterranean buffalo, ranging from lymphocytes to heart, bone marrow, spleen, and reproductive organs and representing a wide range of cell types. From the CRA002325 project, 24 tissues, including adipose, womb, different brain Brodmann areas, forelimb, hindlimb, medulla, heart, cerebellum, hypothalamus, pineal, kidney, tongue, spleen, ovary, liver, lung, and longissimus, from swamp buffalo were used in this study. In addition, RNAseq data of buffalo milk samples at different stages of lactation (early, middle, and late) were downloaded from the NCBI SRA database with the accession number PRJNA453843, which was used to investigate the differential expression of the selected OAT genes in buffalo milk tissues. First, the quality control analysis was performed using TrimGalore v0.6.6 software for the raw data. Subsequently, the clean data were aligned to the buffalo genome (UOA_WB_1) using HISAT v2.2.1 software [20] with default parameters. The count matrix and transcripts per million (TPM) values for each gene were calculated using StringTie v2.1.3 software [21] and DESeq2 v3.11 [22] R-package, respectively. The oneto-one orthologous OAT genes in selected tissue samples were selected and compared between river and swamp buffalo, as described by Yu et al. [23]. The heat maps of TPM values for the buffalo OAT genes were performed using TBtools (v1.051) software [15].

\section{Results}

\subsection{Identification and Phylogenetic Analysis of OAT Gene Family}

To explore the potential function of the OAT family between river and swamp buffalo, we first performed family member identification. A total of 42 non-redundant protein sequences encoded by 17 OAT genes were predicted from the river and swamp buffalo genome (Table 1). Interestingly, these OAT genes clustered into three groups based on the phylogenetic analysis (Figure 1). Group 1 was composed of 5 OAT genes (SLCO1C1, SLCO1A2, SCLO1B3, SCLO3A1, and SCLO2B1), while Group 3 had only the SCLO5A1 gene. Group 2 contained SCLO4C1, SCLO4A1, and SCLO6A1 genes. The constructed dendrogram further showed that the buffalo OAT family was most closely related to the other representative mammals.

Table 1. Features of the predicted OAT protein sequences in buffalo.

\begin{tabular}{ccccccc}
\hline Species & Gene & CHR & Protein ID & Length & Mw (kDa) & pI \\
\hline river & SLCO1A2 & Chr4 & XP_006067688.1 & 666 & 73.79 & 7.09 \\
river & SLCO1C1 & Chr4 & XP_006067684.2 & 712 & 78.46 & 9.02 \\
river & SLCO1B3 & Chr4 & XP_025139143.1 & 689 & 75.45 & 8.71 \\
river & SLCO3A1 & Chr20 & XP_025127060.1 & 692 & 74.38 & 6.94 \\
river & SLCO2A1 & Chr1 & XP_006051482.1 & 644 & 70.2 & 8.81 \\
river & SLCO2B1 & Chr16 & XP_006074131.1 & 708 & 76.67 & 7.93 \\
river & SLCO4C1 & Chr9 & XP_006069687.1 & 719 & 77.4 & 7.00 \\
river & SLCO5A1 & Chr15 & XP_006073179.2 & 846 & 92.13 & 7.89 \\
river & SLCO4A1 & Chr14 & XP_006072365.2 & 761 & 81.19 & 7.55 \\
river & SLCO6A1 & Chr9 & XP_025147965.1 & 731 & 79.8 & 8.52 \\
swamp & SLCO1C1 & Chr1 & GWHPAAJZ000564 & 1222 & 133.66 & 8.31 \\
swamp & SLCO1A2 & Chr1 & GWHPAAJZ000565 & 666 & 73.81 & 7.09 \\
swamp & SLCO2A1 & Chr2 & GWHPAAJZ009028 & 644 & 70.2 & 8.81 \\
swamp & SLCO4C1 & Chr1 & GWHPAAJZ002472 & 719 & 77.49 & 6.82 \\
swamp & SLCO5A1 & Chr14 & GWHPAAJZ005023 & 846 & 92.13 & 7.89 \\
swamp & SLCO4A1 & Chr13 & GWHPAAJZ004480 & 761 & 81.2 & 7.64 \\
swamp & SLCO6A1 & Chr1 & GWHPAAJZ002473 & 933 & 100.78 & 7.97 \\
\hline Ne. CHR
\end{tabular}

Note. CHR: buffalo chromosome; Mw: molecular weight; pI: isoelectric points. 


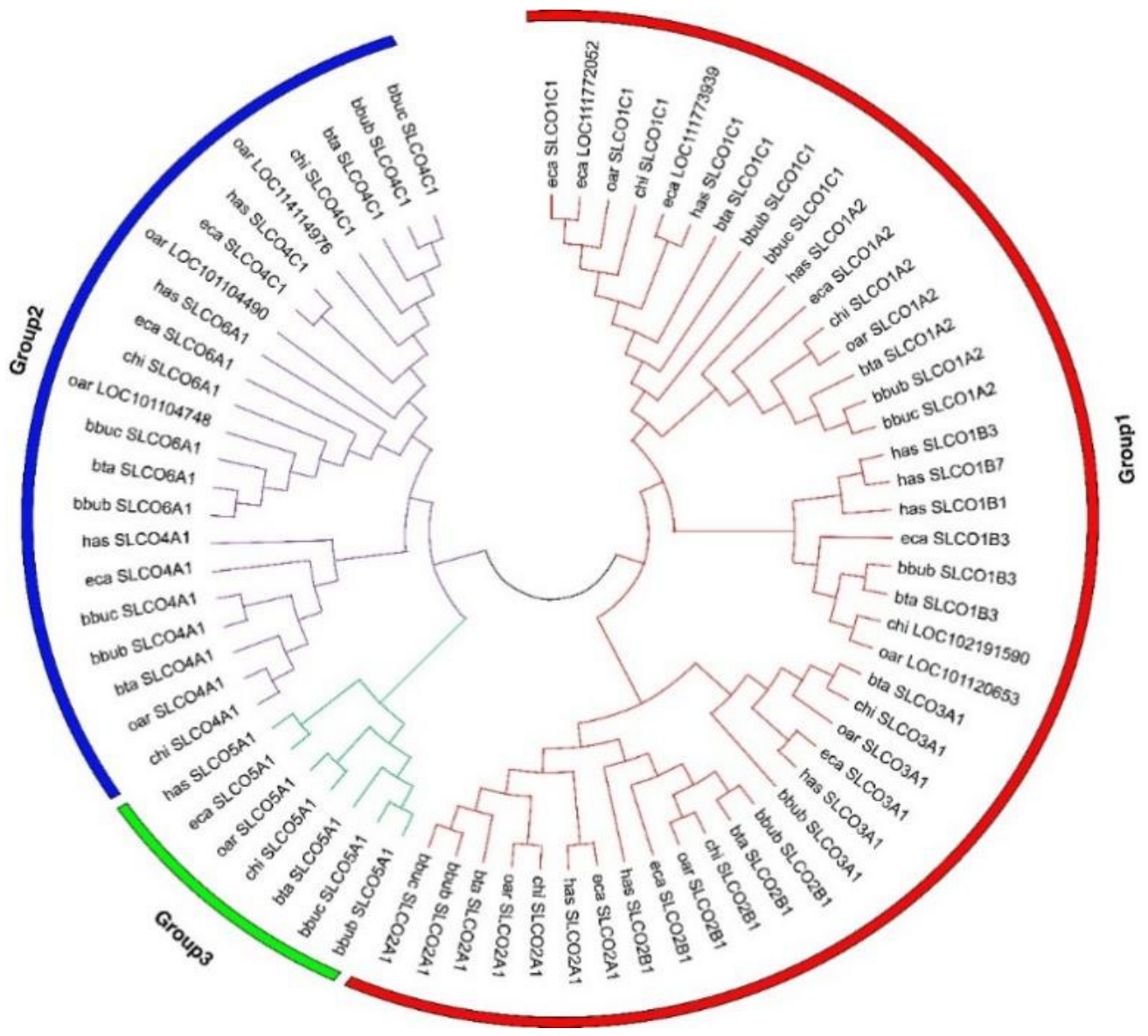

Figure 1. Phylogenetic relationship of OAT proteins in seven mammals. Line with different colors indicates different groups. Different colored circles indicate different groups. River buffalo: bbub; swamp buffalo: bbuc; cattle: bta; goat: chi; sheep: oar; horse: eca; human: has.

\subsection{Chromosome Location and Gene Duplication Analysis of OAT Gene Family}

A total of 10 OAT genes were found to be randomly distributed on 7 chromosomes of river buffalo, while the 7 OAT genes were randomly located on 4 chromosomes of swamp buffalo (Figure 2A). Interestingly, these genes were mainly located on the proximate or the distal ends of the chromosomes. Gene duplication analysis revealed that four pairs of OAT genes exhibited tandem duplication in the studied buffalo: SLCO1B3-SLCO1A2 and SLCO6A1-SLCO4C1 in river buffalo; SLCO1C1-SLCO1A2 and SLCO4C1-SLCO6A1 in swamp buffalo. Two pairs of genes (SLCO3A1-SLCO4C1 and SLCO4A1-SLCO5A1) exhibited segmental duplication in river buffalo. Positive selection analyses further revealed that the $\mathrm{Ka} / \mathrm{Ks}$ ratios of all the duplicated OAT gene pairs in buffalo were less than 1, suggesting that they underwent purifying selection. Divergence times of all duplicated gene pairs ranged from 41.545 to 96.155 Mya (Table 2). For the OAT gene family, five OAT gene pairs were orthologous between the two subspecies (Figure 2B), including SLC2A1, SLCO3A1-SLCO4C1, SLCO4A1, SLCO5A1, and SLCO6A1-SLCO4C1 (Table 3). Divergence times of all orthologous gene pairs ranged from 0.063 to 55.210 Mya. More importantly, we found that the SLCO3A1 and SLCO4C1 gene pair was orthologous between the two subspecies (Figure 2B), while only the segmental duplication event occurred in the river buffalo population (Figure 2A). The divergence times of this orthologous gene pair occurred at 46.857 Mya (Table 3), while the segmental event started with 61.032 Mya (Table 2). 


\section{Gene duplication and collinear analyses of river and swamp buffalo}

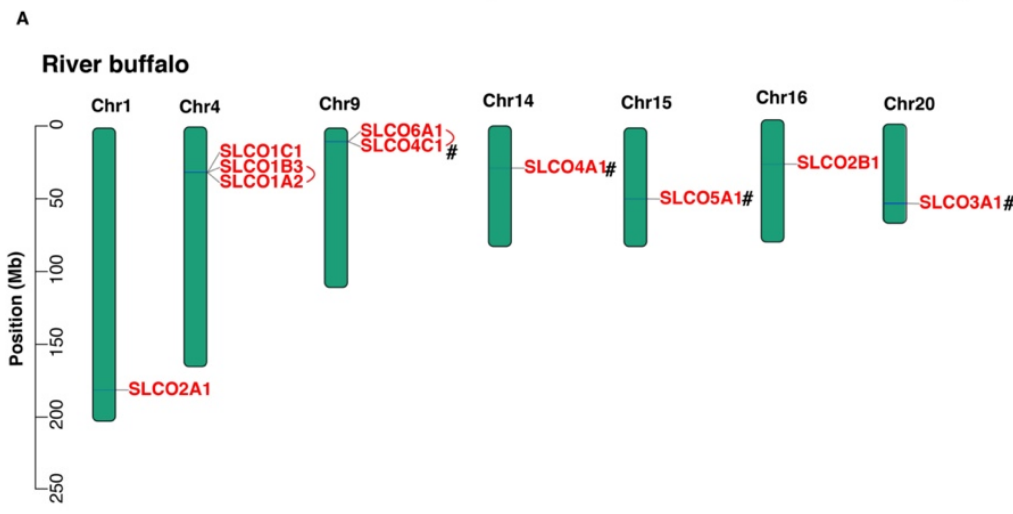

\section{Swamp buffalo}

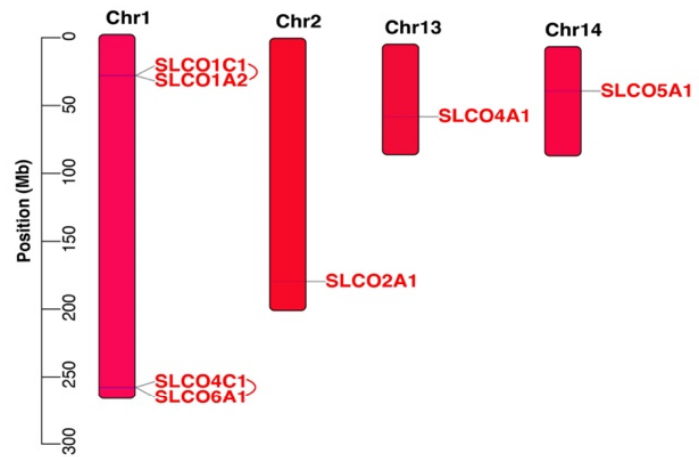

B

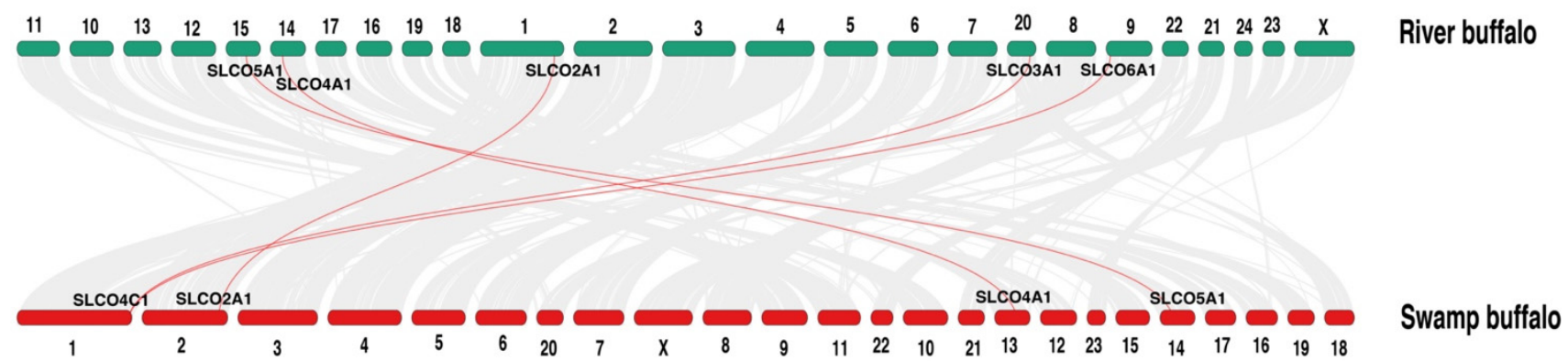

Figure 2. Gene duplication of river and swamp buffalo OAT genes (A) and their collinear analysis (B). The tandem duplicated genes are marked by a red line, and segmentally duplicated genes are indicated by "\#."

Table 2. The Ka/Ks ratios and divergence times for each pair of duplicated OAT genes in buffalo subspecies.

\begin{tabular}{|c|c|c|c|c|c|c|c|}
\hline Subspecies & Seq1 & Seq2 & Type & Ka & Ks & $\mathrm{Ka} / \mathrm{Ks}$ & Date (Mya) \\
\hline \multirow[t]{4}{*}{ River } & SLCO1B3 & SLCO1A2 & tandem & 0.573 & 1.664 & 0.344 & 66.014 \\
\hline & SLCO6A1 & SLCO4C1 & tandem & 0.546 & 1.047 & 0.522 & 41.545 \\
\hline & SLCO3A1 & SLCO4C1 & Segment & 0.746 & 1.538 & 0.485 & 61.032 \\
\hline & SLCO4A1 & SLCO5A1 & Segment & 0.718 & 2.180 & 0.329 & 86.518 \\
\hline \multirow[t]{2}{*}{ Swamp } & SLCO1C1 & SLCO1A2 & tandem & 0.512 & 2.423 & 0.211 & 96.155 \\
\hline & SLCO4C1 & SLCO6A1 & tandem & 0.564 & 1.063 & 0.530 & 42.198 \\
\hline
\end{tabular}

Note. Ka: nonsynonymous substitution rate; Ks: synonymous substitution rate; Mya: million years ago.

Table 3. The Ka/Ks ratios and divergence times for each pair of orthologous OAT genes in buffalo.

\begin{tabular}{cccccc}
\hline Seq1/River Buffalo & Seq2/Swamp Buffalo & Ka & Ks & Ka/Ks & Date (Mya) \\
\hline SLCO2A1 & SLCO2A1 & 0.001 & 0.008 & 0.118 & 0.302 \\
SLCO6A1 & SLCO4C1 & 0.861 & 1.391 & 0.619 & 55.210 \\
SLCO4A1 & SLCO4A1 & 0.723 & 1.165 & 0.620 & 46.238 \\
SLCO5A1 & SLCO5A1 & 0.000 & 0.002 & 0.000 & 0.063 \\
SLCO3A1 & SLCO4C1 & 0.811 & 1.181 & 0.686 & 46.857 \\
\hline
\end{tabular}

Note. Ka: nonsynonymous substitution rate; Ks: synonymous substitution rate; Mya: million years ago.

\subsection{Sequence Characteristics of OAT Gene Family in Buffalo}

To explore the structural characteristics of buffalo OAT members, motif pattern and gene structure analyses were performed considering their phylogenetic relationships (Figure S1). Nine and eight conserved motifs of OAT protein sequences in the river and swamp buffalo, respectively, were annotated as the OATP domain after the Pfam search (Figure S1; Table S1), while motif1 was Kazal_2 dominant among them. Interestingly, 
the buffalo OAT gene family had a similar motif pattern in the same group. Although the introns and UTRs structure varied greatly between river (Figure S1A) and swamp (Figure S1B) buffalo, buffalo OAT genes in the same groups had similar exon and intron numbers, which confirm our previous classification process.

Moreover, we further explored the motif and TFBS patterns of the orthologous SLCO3A1 and SLCO4C1 gene pair between the two subspecies and the segmentally duplicated gene pair (SLCO3A1-SLCO4C1) in the river buffalo (Figure 3). The results revealed that the buffalo SLCO4C1 had nine motifs, including six OATP domains, one OFCC1, and one Kazal_2 domain (Figure 3A), while the SLCO3A1 had only four OATP domains. The TFBS analysis detected 19 cis-elements in the promoter regions of the two genes through the JASPAR2020 database (Figure 3A). Interestingly, the detected numbers of the homeodomain factors, fork head/winged helix factors, and $\mathrm{C} 2 \mathrm{H} 2$ zinc finger factors were the top three members of the SLCO4C1 gene in the river and swamp buffalo populations. For the SLCO3A1 gene, the top three elements were the homeodomain factors, $\mathrm{C} 2 \mathrm{H} 2$ zinc finger factors, and nuclear receptors with $\mathrm{C} 4$ zinc fingers (Figure $3 \mathrm{~B})$. These results suggested that the buffalo SLCO3A1 gene might have different biological functions compared to the SLCO4C1 gene.

\section{TFBS patterns of SLCO3A1 and SCLO4C1 in buffalo subspecies}

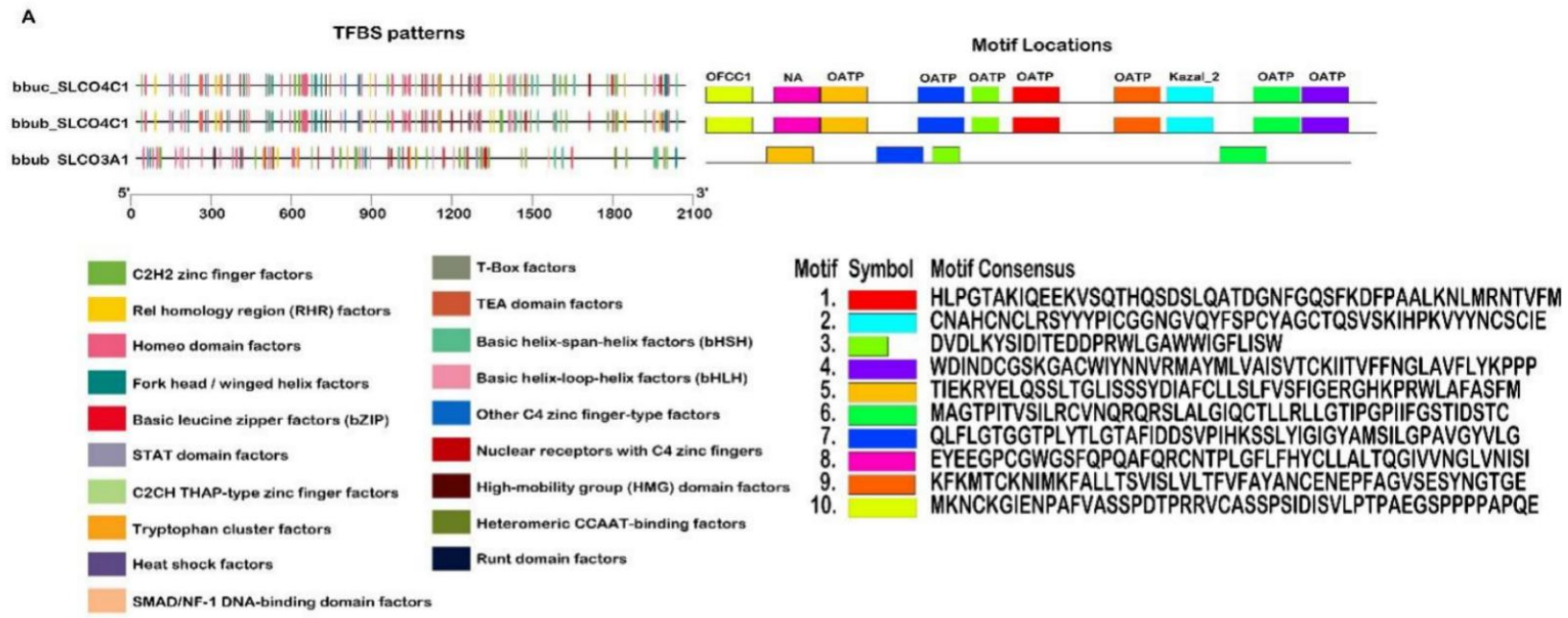

B

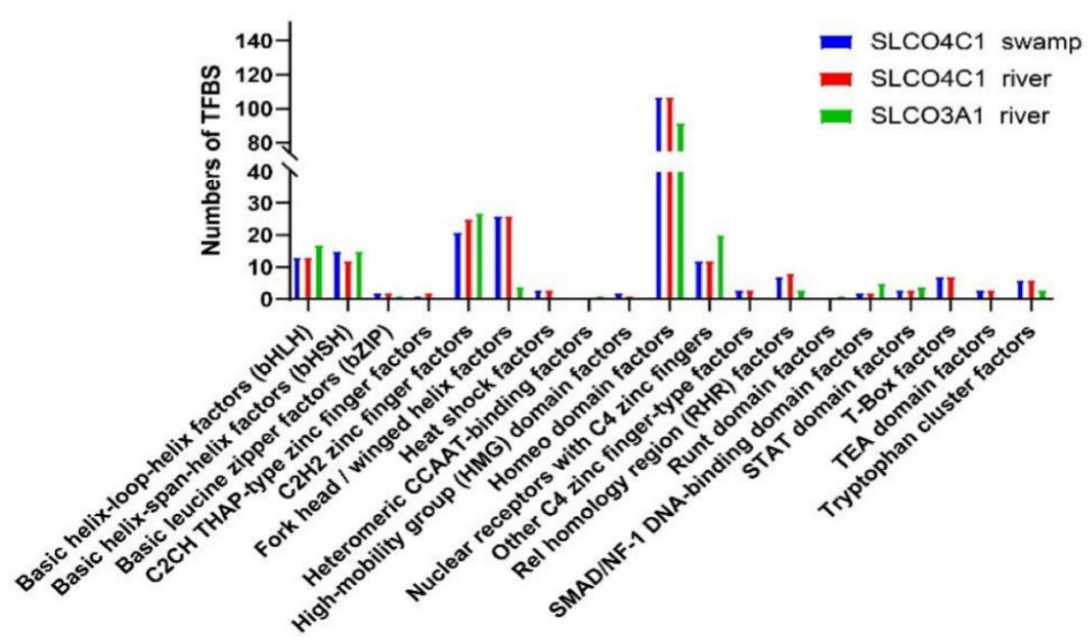

Figure 3. The gene structure and TFBS patterns of SLCO3A1 and SCLO4C1 in buffalo subspecies. (A) The TFBS and motif patterns of SLCO3A1 and SCLO4C1 between the two subspecies. (B) The number of TFBS of SLCO3A1 and SCLO4C1 between the two subspecies. 


\subsection{Expression Pattern Analyses of OAT Gene Family in Buffalo}

Using RNA-seq data from different tissues, we found that most OAT genes had a broad-spectrum expression pattern (Figure 4A,B). Meanwhile, different OAT genes in the same group had a similar expression pattern in the river (Figure 4A) and swamp (Figure 4B) buffalo. Among the clustering groups, Group 1 OAT genes (except for SLCO1C1) had a higher expression level than that of Group 2 (Figure 4A,B). Moreover, we compared the mRNA expression level of orthologous OAT genes between river and swamp buffalo, and the results showed that most genes (except for the SLCO1A2) in Group 1 had a relatively higher expression level in most river tissues, while the Group 2 genes with higher expression level were found in most swamp tissues (Figure 4C). Furthermore, four OAT genes were detected in the milk tissue of river buffalo (Figure 4D). Three OAT genes, namely, SLCO2B1, SLCO3A1, and SLCO4A1, exhibited higher mRNA expression levels than those of the SLCO4C1 gene. Higher expression levels of SLCO2B1 and SLCO3A1 genes were observed at the early- and mid-lactation stages, while the greater expression level of SLCO4A1 gene occurred in late lactation. These results suggest that different Group 1 OAT genes might have a stage-specific expression pattern.

A

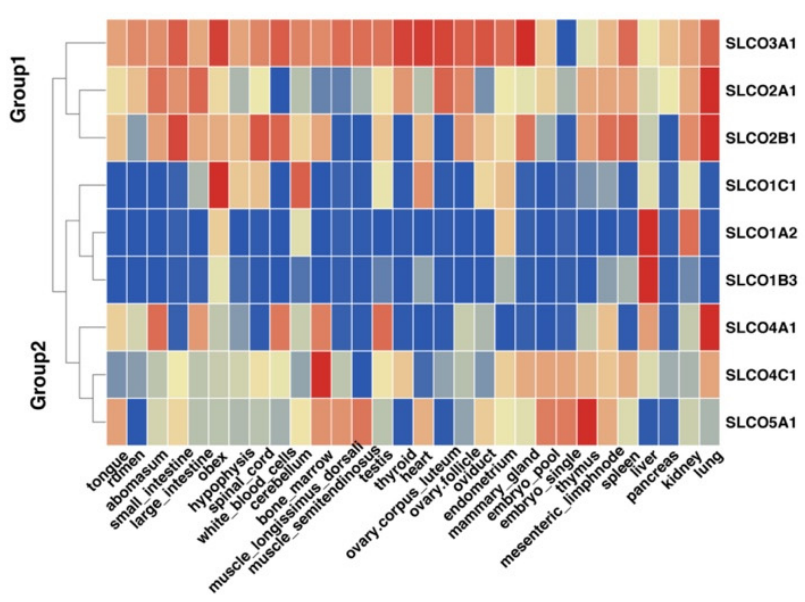

C

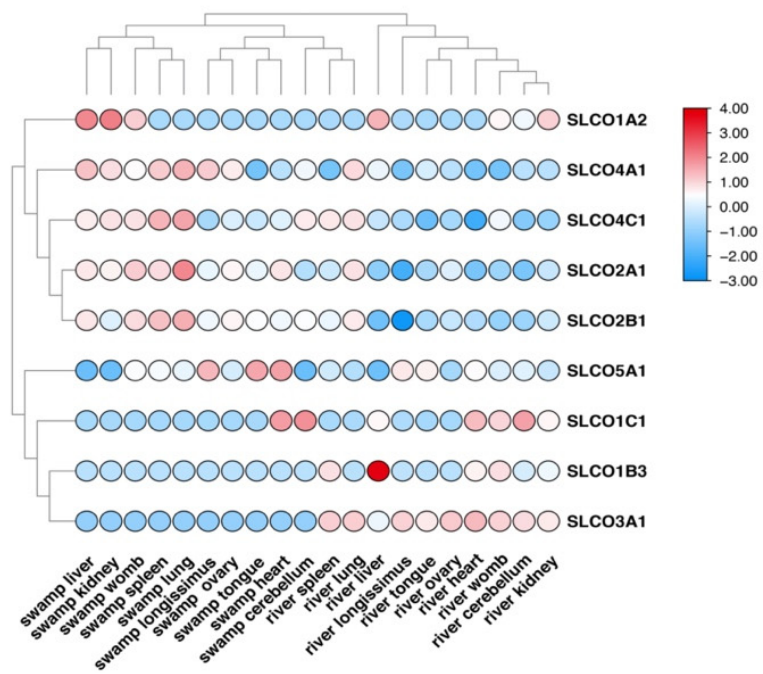

B

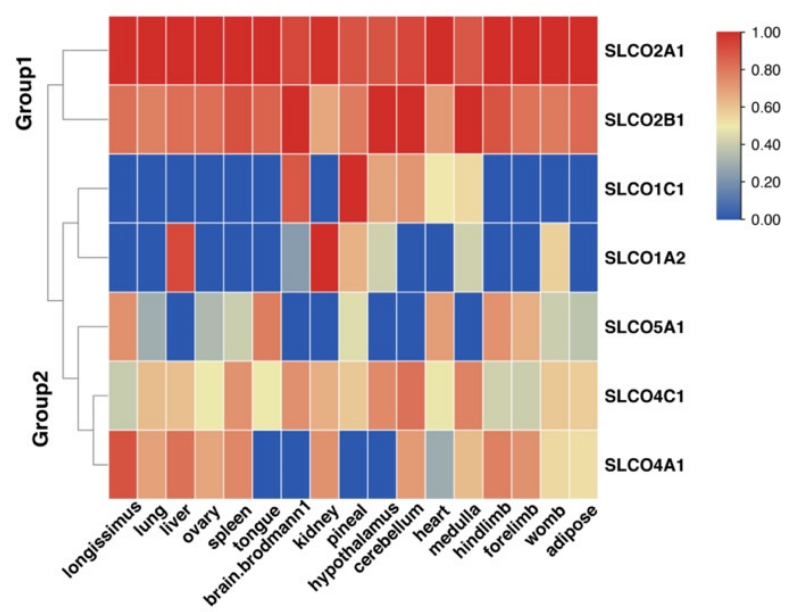

D

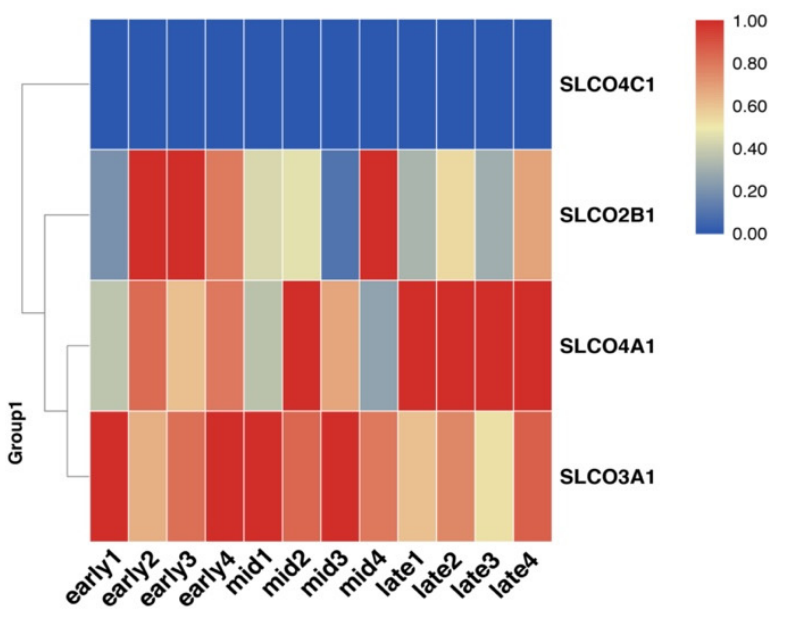

Figure 4. The expression patterns of OAT genes in buffalo subspecies. (A) The expression distribution of OAT genes in river buffalo tissues. (B) The expression distribution of OAT genes in swamp buffalo tissues. (C) The expression differential patterns of orthologous OAT genes between river and swamp buffalo. (D) The expression patterns of OAT genes in buffalo milk samples at different lactation. 


\section{Discussion}

Gene family analysis has attracted widespread attention of both the research and farming communities owing to their contribution to a better understanding of the potential biological function affecting phenotypic diversity during evolution. It is well known that the OAT gene family plays a vital role in nutrient transport in the mammary gland $[2,24]$. In this context, our study is an attempt to systematically understand the OAT gene family's potential functions affecting milk performance in buffalo through comparative genomics analysis. We identified 42 non-redundant protein sequences encoded by 17 OAT genes from the river and swamp buffalo genome. These protein sequences are clustered into three groups based on the phylogenetic analysis. The buffalo OAT gene family had a similar motif pattern and gene structure in the same buffalo group. To dissect the functional divergence of OAT gene family in the two buffalo subspecies, we performed tissue expression pattern analysis of the OAT genes. Our data showed that these OAT genes in the same group had a similar tissue expression pattern in river and swamp buffalo. Except for the SLCO1C1 gene, Group 1 genes had higher expression levels than those of Group 2 genes. These results are in agreement with those obtained by Nigam et al. [1]. Evidence showed that genes in the Group 1 might be related to the uptake of hormones and organic ions in different tissues, such as the SLCO1C1 gene for the uptake of thyroid hormones in brain tissues [25], SLCO1A2 gene for the cellular uptake of organic ions in the liver [26], SLCO2A1 gene for the uptake and clearance of prostaglandins in numerous tissues [27], and SLCO2B1 gene for the regulation of placental uptake of sulfated steroids [28]. For Group 2, SLCO4A1 gene has shown to be involved in transporting estrogen and its various precursors and metabolites, prostaglandin E2, and thyroid hormones [29,30]. The SLCO4C1 gene was reported to be expressed at the basolateral membrane of the proximal tubule [31], and the SCLO6A1 gene also predominantly expressed in the testis, with a limited expression in the epididymis [32]. Moreover, Group 3 has only the SLCO5A1 gene, which might be a non-classical OAT family member involved in the processes of the cell shape reorganization [33].

Gene tandem and segmental duplication have significant roles in biological evolution. In this study, we observed that four gene pairs were duplicated in river buffalo through tandem or segmental duplication, while the swamp buffalo had two pairs of tandem duplicated genes. Collinearity analysis showed five orthologous genes in the river and swamp buffalo genomes. It was noted that the divergence times of the orthologous gene pair (SLCO3A1-SLCO4C1) between river and swamp buffalo occurred at 46.857 Mya. In addition, this gene pair had a segmental event in river buffalo, and its divergence time started with $61.032 \mathrm{Mya}$. These findings suggested that the SLCO4C1 gene formed an orthologous gene (SLCO3A1) in river buffalo through a segmental duplication event. In contrast, the loss event of the SLCO3A1 gene might have occurred in swamp buffalo during evolution. Moreover, RNA-data of mammary gland tissue in river buffalo showed that the Group 1 OAT genes, including SLCO2B1, SLCO3A1, and SLCO4A1, exhibited higher mRNA expression levels than that of $S L C O 4 C 1$ gene. Moreover, higher expression levels of SLCO2B1 and SLCO3A1 genes were observed at the early- and mid-lactation stages, while the higher expression level of SLCO4A1 was noticed in late lactation. Both SLCO3A1 and SLCO4C1 genes were orthologous between the river and swamp buffalo. More importantly, we found that the segmental duplication event might be involved in the expression pattern of the SLCO4C1 gene in the river buffalo, resulting in a novel river-specific duplicated gene (SLCO3A1). On the other hand, the swamp buffalo lost this duplicated gene. Previous studies reported that segmental duplication events play a vital role in forming novel gene functions $[7,34,35]$. In this regard, we presume that the segmental duplication event of OAT gene family has a positive effect on enhancing milk production performance in river buffalo. In other words, the loss of SLCO3A1 gene in swamp buffalo may be one of the reasons leading to the low milk performance of the swamp buffalo compared to that of river buffalo. However, this inference needs to be confirmed through further investigation.

Considering the function characteristics of SLCO3A1 and SLCO4C1 genes during evolution, we further explored the TFBS patterns of the two orthologous genes between 
the two subspecies. The results showed that the detected numbers of the Homeo-domain factors, Fork-head/winged helix factors, and $\mathrm{C} 2 \mathrm{H} 2$ zinc finger factors were the top three members of the SLCO4C1 gene in river and swamp buffalo populations. For the SLCO3A1 gene, the top three elements were the Homeo-domain factors, $\mathrm{C} 2 \mathrm{H} 2$ zinc finger factors, and Nuclear receptors with C4 zinc fingers (Figure 3B). Evidence revealed that Homeo-domain factors play a fundamental role in a diverse set of functions including body plan specification, pattern formation, and cell fate determination during metazoan development [36]. The Fork-head/winged helix factors were reported to play important regulatory roles in a wide variety of biological functions, including cell proliferation, immunity, apoptosis, and metabolism [37]. The $\mathrm{C} 2 \mathrm{H} 2$ zinc finger factors were known to be involved in many cellular processes including DNA-binding, RNA-binding, protein-protein interaction, and protein folding, etc. [38]. Porter et al. [39] reported that the Nuclear receptors with C4 zinc fingers have a unique role in the maintenance of cellular homeostasis, gene expression regulation in embryogenesis, and tissue development. These results suggested that the buffalo SLCO3A1 gene might have different biological functions compared to the SLCO4C1 gene.

\section{Conclusions}

In summary, we detected 17 buffalo OAT genes. The river-specific expansions and homologous loss of OAT genes were observed in the two buffalo subspecies during the evolutionary process. Notably, the duplicated SLCO3A1 gene of river buffalo showed a higher expression level in the mammary gland tissue in comparison with that of the swamp buffalo. These results provide useful information for illuminating the biological functions of the OAT family genes affecting milk performance in buffalo.

Supplementary Materials: The following are available online at https:/ / www.mdpi.com/article / 10.3390/genes12091394/s1, Table S1. Ten different motifs are commonly observed in the buffalo OAT family. Figure S1: Phylogenetic relationships, motif pattern, and gene structure of OAT gene family in the river (A) and swamp (B) buffalo. Ten putative motifs are indicated in different colored boxes. The blue box, black line, and green box represent the coding sequence (CDS), intron, and untranslated region (UTR), respectively.

Author Contributions: T.D. designed the study and analyzed the data; H.E.R. and T.D. interpreted the data; T.D. and X.M. wrote the drafted manuscript; T.D., X.M., S.L., A.L. and H.E.R. reviewed the paper. All authors have read and agreed to the published version of the manuscript.

Funding: This study was funded by the Fundamental Research Funds for the Central Universities (2662020DHPY002) and the Natural Science Foundation of Guangxi (2020GXNSFDA297032).

Institutional Review Board Statement: Animal Care and Use Committee approval was not required for this study because the data were obtained from an existing database.

Informed Consent Statement: Not applicable.

Data Availability Statement: Not applicable.

Conflicts of Interest: The authors declare no conflict of interest.

\section{References}

1. Nigam, S.K.; Bush, K.T.; Martovetsky, G.; Ahn, S.Y.; Liu, H.C.; Richard, E.; Bhatnagar, V.; Wu, W. The organic anion transporter (OAT) family: A systems biology perspective. Physiol. Rev. 2015, 95, 83-123. [CrossRef] [PubMed]

2. García-Lino, A.M.; Álvarez-Fernández, I.; Blanco-Paniagua, E.; Merino, G.; Álvarez, A.I. Transporters in the Mammary GlandContribution to Presence of Nutrients and Drugs into Milk. Nutrients 2019, 11, 2372. [CrossRef] [PubMed]

3. Ibeagha-Awemu, E.M.; Peters, S.O.; Akwanji, K.A.; Imumorin, I.G.; Zhao, X. High density genome wide genotyping-bysequencing and association identifies common and low frequency SNPs, and novel candidate genes influencing cow milk traits. Sci. Rep. 2016, 6, 31109. [CrossRef] [PubMed]

4. Machado, H.E.; Jui, G.; Joyce, D.A.; Reilly, C.R., 3rd; Lunt, D.H.; Renn, S.C. Gene duplication in an African cichlid adaptive radiation. BMC Genom. 2014, 15, 161. [CrossRef] [PubMed] 
5. Feng, X.; Jiang, J.; Padhi, A.; Ning, C.; Fu, J.; Wang, A.; Mrode, R.; Liu, J.F. Characterization of genome-wide segmental duplications reveals a common genomic feature of association with immunity among domestic animals. BMC Genom. 2017, 18, 293. [CrossRef]

6. Panchy, N.; Lehti-Shiu, M.; Shiu, S.-H. Evolution of Gene Duplication in Plants. Plant Physiol. 2016, 171, 2294-2316. [CrossRef]

7. Katju, V.; Lynch, M. On the formation of novel genes by duplication in the Caenorhabditis elegans genome. Mol. Biol. Evol. 2006, 23, 1056-1067. [CrossRef]

8. Hughes, A.L. Gene duplication and the origin of novel proteins. Proc. Natl. Acad. Sci. USA 2005, 102, 8791-8792. [CrossRef]

9. Rehman, S.U.; Nadeem, A.; Javed, M.; Hassan, F.-U.; Luo, X.; Khalid, R.B.; Liu, Q. Genomic Identification, Evolution and Sequence Analysis of the Heat-Shock Protein Gene Family in Buffalo. Genes 2020, 11, 1388. [CrossRef]

10. Meng, D.; Cao, Y.; Chen, T.; Abdullah, M.; Jin, Q.; Fan, H.; Lin, Y.; Cai, Y. Evolution and functional divergence of MADS-box genes in Pyrus. Sci. Rep. 2019, 9, 1266. [CrossRef]

11. Wahid, H.; Rosnina, Y. Buffalo: Asia. Ref. Modul. Food Sci. 2016. [CrossRef]

12. Borghese, A.; Moioli, B. Buffalo: Mediterranean Region. Ref. Modul. Food Sci. 2016. [CrossRef]

13. UniProt Consortium. UniProt: A worldwide hub of protein knowledge. Nucleic Acids Res. 2019, 47, D506-D515. [CrossRef] [PubMed]

14. Potter, S.C.; Luciani, A.; Eddy, S.R.; Park, Y.; Lopez, R.; Finn, R.D. HMMER web server: 2018 update. Nucleic Acids Res. 2018, 46, W200-W204. [CrossRef]

15. Chen, C.; Chen, H.; Zhang, Y.; Thomas, H.R.; Frank, M.H.; He, Y.; Xia, R. TBtools: An Integrative Toolkit Developed for Interactive Analyses of Big Biological Data. Mol. Plant 2020, 13, 1194-1202. [CrossRef] [PubMed]

16. Lynch, M.; Conery, J.S. The evolutionary fate and consequences of duplicate genes. Science 2000, 290, 1151-1155. [CrossRef]

17. Sun, T.; Shen, J.; Achilli, A.; Chen, N.; Chen, Q.; Dang, R.; Zheng, Z.; Zhang, H.; Zhang, X.; Wang, S.; et al. Genomic analyses reveal distinct genetic architectures and selective pressures in buffaloes. GigaScience 2020, 9, giz166. [CrossRef] [PubMed]

18. Kumar, S.; Stecher, G.; Li, M.; Knyaz, C.; Tamura, K. MEGA X: Molecular Evolutionary Genetics Analysis across Computing Platforms. Mol. Biol. Evol. 2018, 35, 1547-1549. [CrossRef]

19. Tan, G.; Lenhard, B. TFBSTools: An R/bioconductor package for transcription factor binding site analysis. Bioinformatics 2016, 32, 1555-1556. [CrossRef] [PubMed]

20. Pertea, M.; Kim, D.; Pertea, G.M.; Leek, J.T.; Salzberg, S.L. Transcript-level expression analysis of RNA-seq experiments with HISAT, StringTie and Ballgown. Nat. Protoc. 2016, 11, 1650-1667. [CrossRef]

21. Kovaka, S.; Zimin, A.V.; Pertea, G.M.; Razaghi, R.; Salzberg, S.L.; Pertea, M. Transcriptome assembly from long-read RNA-seq alignments with StringTie2. Genome Biol. 2019, 20, 278. [CrossRef] [PubMed]

22. Love, M.I.; Huber, W.; Anders, S. Moderated estimation of fold change and dispersion for RNA-seq data with DESeq2. Genome Biol. 2014, 15, 550. [CrossRef]

23. Yu, L.; Wang, G.D.; Ruan, J.; Chen, Y.B.; Yang, C.P.; Cao, X.; Wu, H.; Liu, Y.H.; Du, Z.L.; Wang, X.P.; et al. Genomic analysis of snub-nosed monkeys (Rhinopithecus) identifies genes and processes related to high-altitude adaptation. Nat. Genet. 2016, 48, 947-952. [CrossRef] [PubMed]

24. Montalbetti, N.; Dalghi, M.G.; Albrecht, C.; Hediger, M.A. Nutrient transport in the mammary gland: Calcium, trace minerals and water soluble vitamins. J. Mammary Gland Biol. Neoplasia 2014, 19, 73-90. [CrossRef] [PubMed]

25. Wirth, E.K.; Schweizer, U.; Köhrle, J. Transport of thyroid hormone in brain. Front. Endocrinol. 2014, 5, 98. [CrossRef] [PubMed]

26. Yang, C.H.; Glover, K.P.; Han, X. Characterization of cellular uptake of perfluorooctanoate via organic anion-transporting polypeptide 1A2, organic anion transporter 4, and urate transporter 1 for their potential roles in mediating human renal reabsorption of perfluorocarboxylates. Toxicol. Sci. 2010, 117, 294-302. [CrossRef]

27. Nakanishi, T.; Tamai, I. Roles of Organic Anion Transporting Polypeptide 2A1 (OATP2A1/SLCO2A1) in Regulating the Pathophysiological Actions of Prostaglandins. AAPS J. 2017, 20, 13. [CrossRef]

28. Ugele, B.; Bahn, A.; Rex-Haffner, M. Functional differences in steroid sulfate uptake of organic anion transporter 4 (OAT4) and organic anion transporting polypeptide 2B1 (OATP2B1) in human placenta. J. Steroid Biochem. Mol. Biol. 2008, 111, 1-6. [CrossRef]

29. Kobayashi, Y.; Nojima, J.; Ohbayashi, M.; Kohyama, N.; Yamamoto, T. Molecular cloning and functional characterization of a novel gene encoding human prostaglandin carrier, hPrC. Yakugaku Zasshi J. Pharm. Soc. Jpn. 2011, 131, 1493-1501. [CrossRef]

30. Ban, D.; Zhang, C.; Zhang, Y. Expression profiles and association between OATP4A1 and PGE (2) in adenomyosis tissue. Int. J. Clin. Exp. Pathol. 2019, 12, 3367-3375.

31. Kuo, K.L.; Zhu, H.; McNamara, P.J.; Leggas, M. Localization and functional characterization of the rat Oatp4c1 transporter in an in vitro cell system and rat tissues. PLoS ONE 2012, 7, e39641. [CrossRef] [PubMed]

32. Fietz, D.; Bakhaus, K.; Wapelhorst, B.; Grosser, G.; Günther, S.; Alber, J.; Döring, B.; Kliesch, S.; Weidner, W.; Galuska, C.E.; et al. Membrane transporters for sulfated steroids in the human testis-Cellular localization, expression pattern and functional analysis. PLoS ONE 2013, 8, e62638. [CrossRef] [PubMed]

33. Sebastian, K.; Detro-Dassen, S.; Rinis, N.; Fahrenkamp, D.; Müller-Newen, G.; Merk, H.F.; Schmalzing, G.; Zwadlo-Klarwasser, G.; Baron, J.M. Characterization of SLCO5A1/OATP5A1, a solute carrier transport protein with non-classical function. PLoS ONE 2013, 8, e83257. [CrossRef]

34. Zhang, P.; Chopra, S.; Peterson, T. A segmental gene duplication generated differentially expressed myb-homologous genes in maize. Plant Cell 2000, 12, 2311-2322. [CrossRef] [PubMed] 
35. Holland, P.W.; Marlétaz, F.; Maeso, I.; Dunwell, T.L.; Paps, J. New genes from old: Asymmetric divergence of gene duplicates and the evolution of development. Philos. Trans. R. Soc. Lond. B Biol. Sci. 2017, 372, 20150480. [CrossRef]

36. Banerjee-Basu, S.; Baxevanis, A.D. Molecular evolution of the homeodomain family of transcription factors. Nucleic Acids Res. 2001, 29, 3258-3269. [CrossRef] [PubMed]

37. Li, J.; Dai, S.; Chen, X.; Liang, X.; Qu, L.; Jiang, L.; Guo, M.; Zhou, Z.; Wei, H.; Zhang, H.; et al. Mechanism of forkhead transcription factors binding to a novel palindromic DNA site. Nucleic Acids Res. 2021, 49, 3573-3583. [CrossRef] [PubMed]

38. Alam, I.; Batool, K.; Cui, D.L.; Yang, Y.Q.; Lu, Y.H. Comprehensive genomic survey, structural classification and expression analysis of $\mathrm{C} 2 \mathrm{H} 2$ zinc finger protein gene family in Brassica rapa L. PLoS ONE 2019, 14, e216071. [CrossRef]

39. Porter, B.A.; Ortiz, M.A.; Bratslavsky, G.; Kotula, L. Structure and Function of the Nuclear Receptor Superfamily and Current Targeted Therapies of Prostate Cancer. Cancers 2019, 11, 1852. [CrossRef] 